archives

of thermodynamics

Vol. 38(2017), No. 3, 63-75

DOI: $10.1515 /$ aoter-2017-0016

\title{
Impact of waste heat recovery systems on energy efficiency improvement of a heavy-duty diesel engine
}

\author{
ZHESHU MA $^{a *}$, HUA CHEN ${ }^{b}$ and YONG ZHANG ${ }^{a}$
}

a College of Automobile and Traffic Engineering, Nanjing Forestry University, Nanjing, Jiangsu, 210037, China

$b$ School of Accounting, Nanjing University of Finance and Economics, Nanjing, China

\begin{abstract}
The increase of ship's energy utilization efficiency and the reduction of greenhouse gas emissions have been high lightened in recent years and have become an increasingly important subject for ship designers and owners. The International Maritime Organization (IMO) is seeking measures to reduce the $\mathrm{CO}_{2}$ emissions from ships, and their proposed energy efficiency design index (EEDI) and energy efficiency operational indicator (EEOI) aim at ensuring that future vessels will be more efficient. Waste heat recovery can be employed not only to improve energy utilization efficiency but also to reduce greenhouse gas emissions. In this paper, a typical conceptual large container ship employing a low speed marine diesel engine as the main propulsion machinery is introduced and three possible types of waste heat recovery systems are designed. To calculate the EEDI and EEOI of the given large container ship, two software packages are developed. From the viewpoint of operation and maintenance, lowering the ship speed and improving container load rate can greatly reduce EEOI and further reduce total fuel consumption. Although the large container ship itself can reach the IMO requirements of EEDI at the first stage with a reduction factor $10 \%$ under the reference line value, the proposed waste heat recovery systems can improve the ship EEDI reduction factor to $20 \%$ under the reference line value.
\end{abstract}

${ }^{*}$ Corresponding Author. Email mazheshu@126.com 
Keywords: Energy efficiency design index; Energy efficiency operational indicator; Waste heat recovery system; Performance analysis; Reduction factor

\section{Nomenclature}

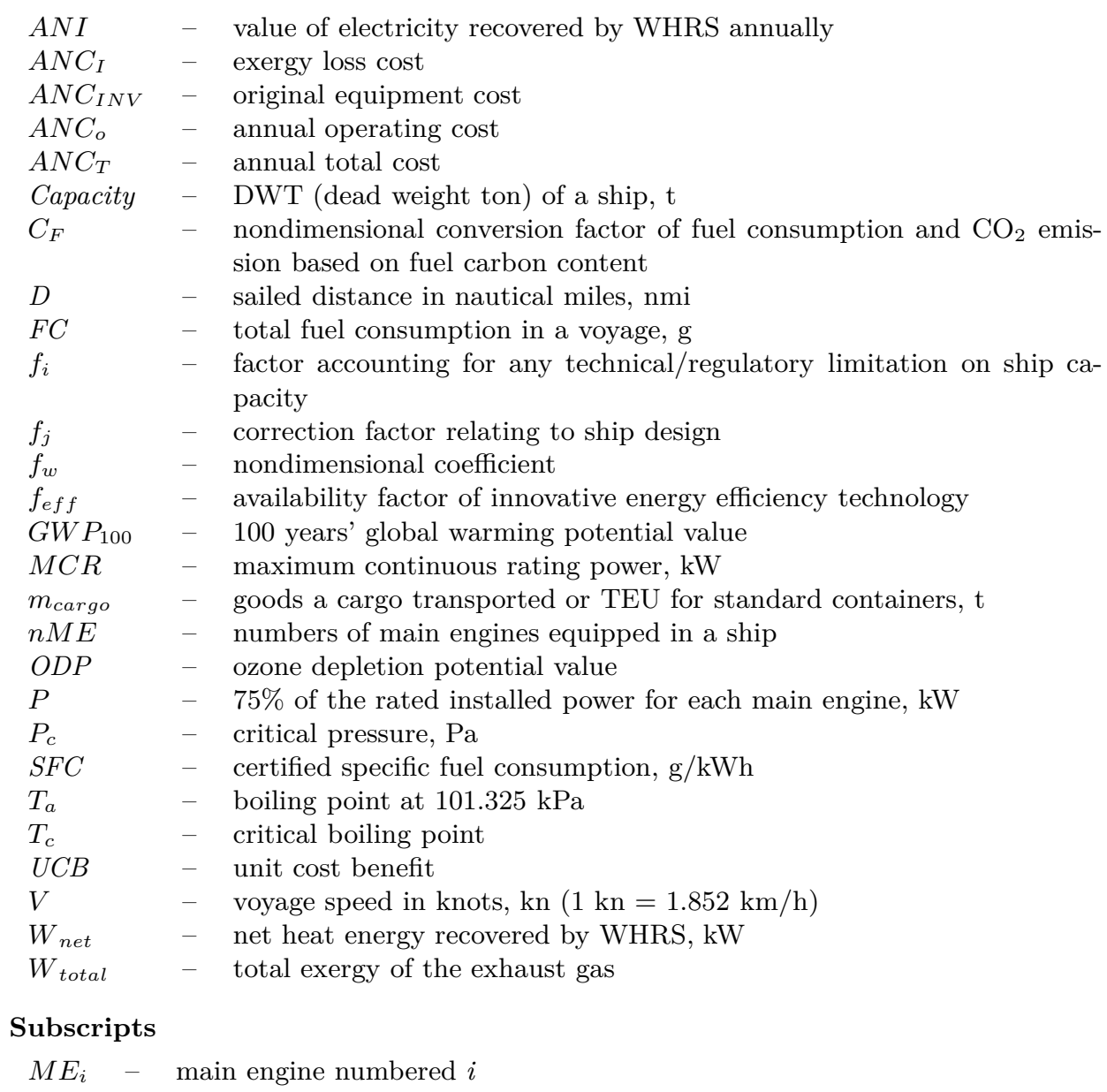

\section{Introduction}

Deriving from the increasing interest in emission reduction and ship operating costs reduction, International Maritime Organization (IMO) has amended two rules to ensure optimal utilization of the fuel used for main engines and auxiliary engines on board ships, i.e., energy efficiency design index (EEDI) and energy efficiency operational indicator (EEOI), which 
are getting even more important with EEDI in place from 2013. The lower the values of EEDI and EEOI, the higher the level of fuel utilization for a specific vessel is. To reduce the values of EEDI and EEOI, various contributing factors can be identified as follows.

To reduce the value of EEDI, several technology strategies can be taken into accounts according to different stages which are demanded by IMO. For instance, a container ship which is above 15000 DWT (dead weight tonnage) should reduce its EEDI by $10 \%$ compared to the reference line value at first stage (from Jan. 1, 2015 to Dec. 31, 2019) and reduce its EEDI by $20 \%$ compared to the reference line value at second stage (from Jan. 1, 2020 to Dec. 31, 2024)[1]. To meet these tough requests, some measures can be taken at first stage, i.e., installation of generators driven by main engine, reduction of resistance, improvement of propulsive efficiency, adoption of microbubble lubrication system and other energy saving technologies while waste heat recovery system, renewable energy (such as wind power, solar power, etc.), the reduction of speed, the use of liquefied natural gas (LNG) fuel, etc. can be taken at second stage.

To reduce the value of EEOI, however, five main operating methods will be firstly considered, i.e., increase of sailed distance and load rate, reduction of time in port and speed, and utilization of waste heat recovery system.

Considering the aspects mentioned above, installation of waste heat recovery system could both reduce the values of EEDI and EEOI for a specific ship so that the level of energy utilization onboard could be further improved while ship's emission and operating costs could be further cut down.

In this paper, a new generation of 10000 TEU (twenty feet equivalent unit) container ship being built is the main study object which has won critical acclaim for environmentally friendly and energy saving. The main engine is an intelligence diesel engine made by MAN B\&W with excellent performances of high energy efficiency, low specific fuel oil consumption, low exhaust gas temperature and low emission. In order to analyze the impact of waste heat recovery system on EEDI and EEOI for this container ship, three exhaust gas waste heat recovery conceptual systems had been proposed and the influences of waste heat recovery system on EEDI and EEOI had been analyzed, meanwhile, some constructive conclusions had been drawn. 


\section{The proposed conceptual systems of WHRS}

Main engine's low exhaust gas temperature is one of the most important factors which affect the choice of the type of waste heat recovery systems (WHRS), especially for large or ultralarge merchant ships. Due to the very low exhaust gas temperature for this container ship's main engine (i.e., $266.8^{\circ} \mathrm{C}$ at normal continuous rating at ISO conditions) [2], organic Rankine cycle (ORC) installation had been considered. Three exhaust gas waste heat recovery conceptual systems had been proposed according to different methods.

\subsection{The WHRS with combined turbines}

Figure 1 shows the WHRS with combined turbines designed for the studied container ship. By bypassing a part of exhaust gas after turbochargers, the total amount of air and exhaust gas will be reduced, the exhaust gas temperature after turbochargers and bypass will increase. The mixed exhaust gas entering the exhaust boiler could have an increase of temperature up to $65{ }^{\circ} \mathrm{C}$ compared to the standard engine at the expense of reducing the energy efficiency of the main engine, increasing specific fuel oil consumption, increasing the efficiency of the turbo-chargers, installing power turbine [3].

\subsection{The WHRS based on Rankine cycle}

Figure 2 shows the WHRS based on Rankine cycle designed for the studied container ship. Exhaust gas after turbochargers enters boiler directly so that superheated steam's temperature would be relatively lower compared to combined turbines waste heat recovery conceptual system.

\subsection{The WHRS based on organic Rankine cycle}

Figure 3 shows the WHRS based on organic Rankine cycle designed for the studied container ship. Different from the two waste heat recovery conceptual systems mentioned above, organic Rankine cycle waste heat recovery conceptual system is not a cogeneration system, i.e., the saturated steam for heating service is produced by auxiliary boiler separately. What's more, organic working fluid could keep dry at the end of expanding process so that there is no need to superheat it. 


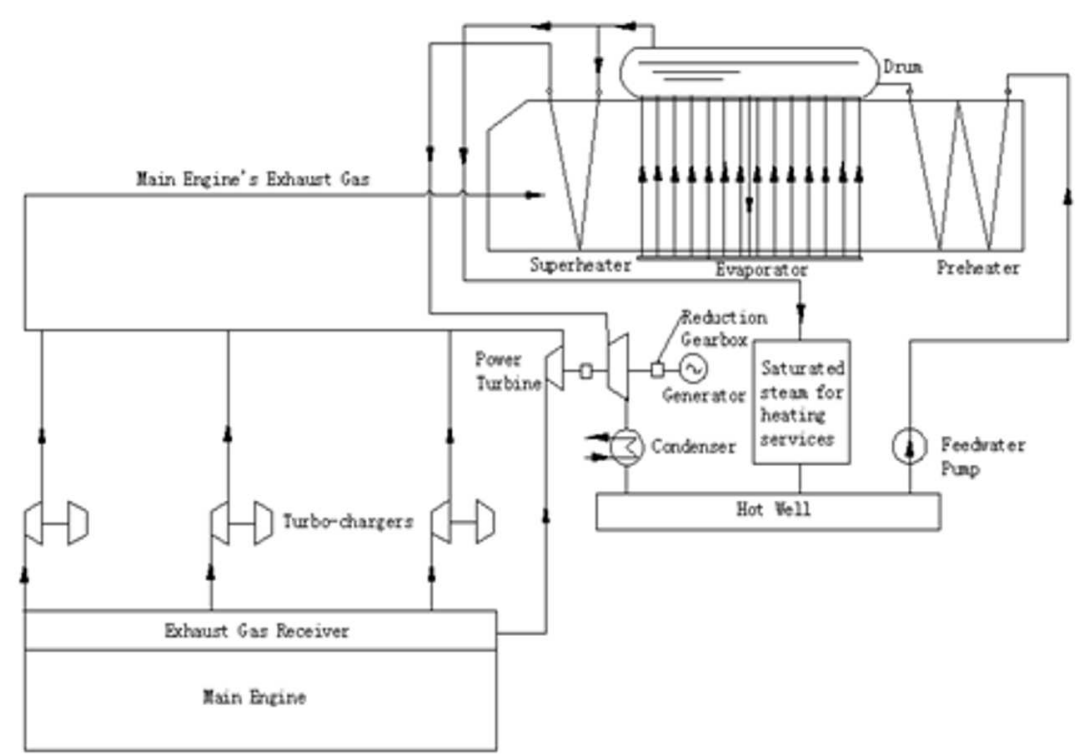

Figure 1: Diagram of combined turbines waste heat recovery conceptual system.

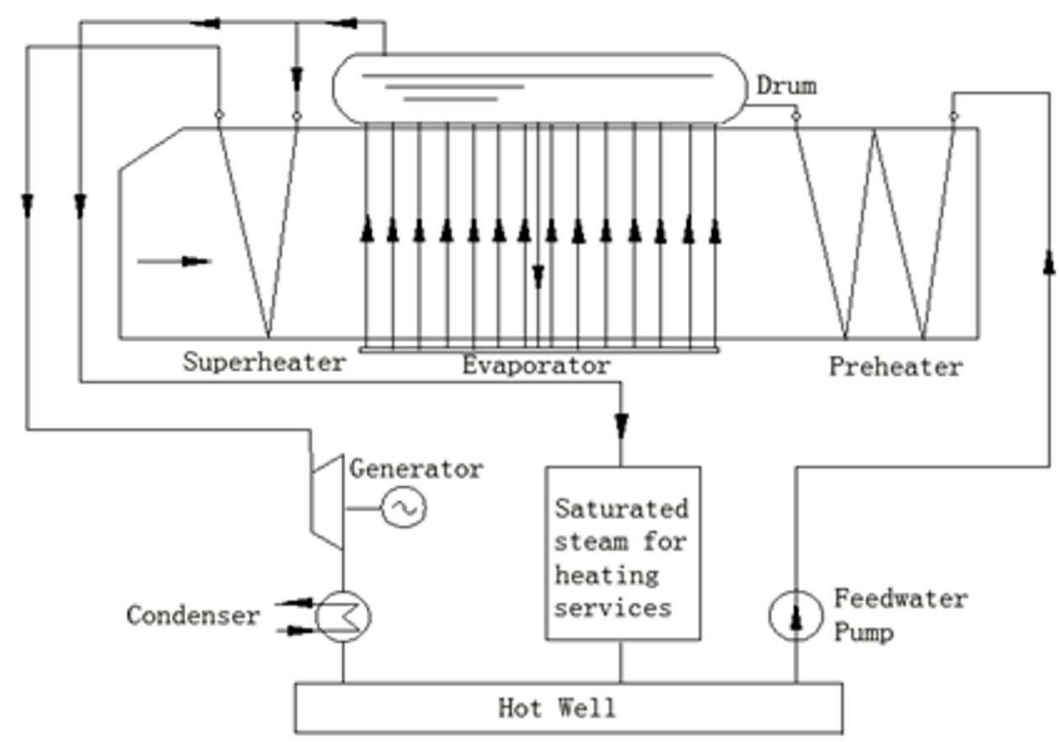

Figure 2: Diagram of Rankine cycle waste heat recovery conceptual system. 
The organic compound selection has been proven to be vital to ORC plant efficiency and optimum performance [7]. Preselection of organic compound is performed under the base of same exhaust gas boiler outlet temperature according to the following criteria: (1) the organic compound should have a critical temperature near the exhaust gas temperature; $(2)$ the standard boiling point should near the ambient air temperature; (3) it should be one of the available organic compound that has been previously studied in the scientific literature or organic compounds that are used in commercial ORC power plants, such as Solkatherm, n-pentane or R134a [8-10].

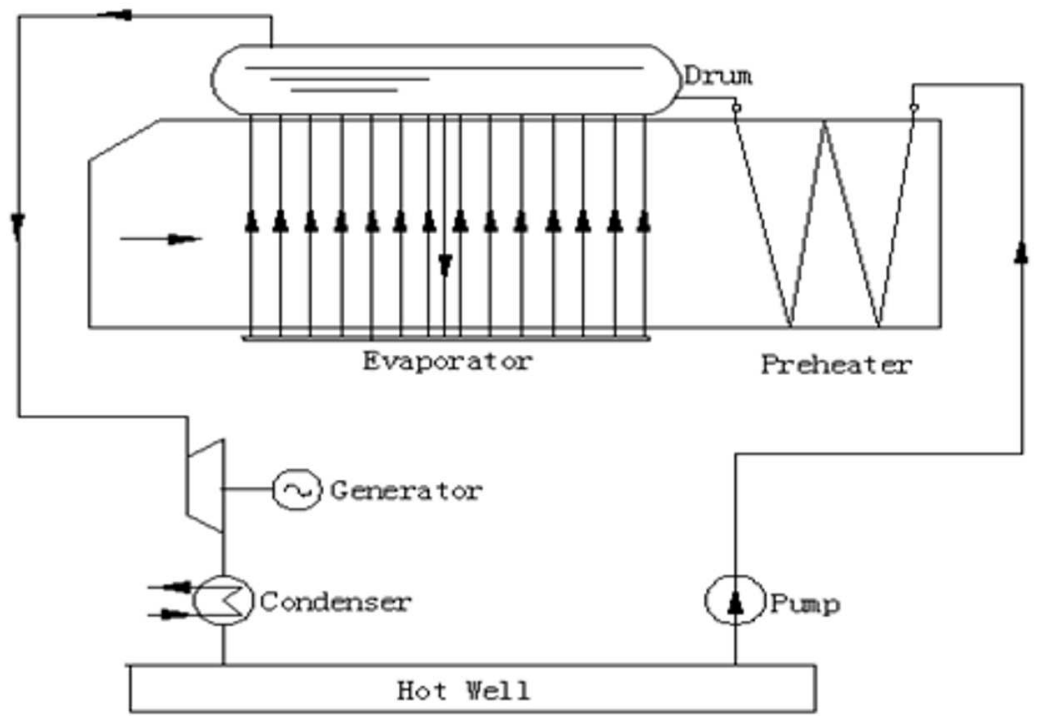

Figure 3: Diagram of organic Rankine cycle waste heat recovery conceptual system.

Table 1 shows the selected organic working fluids which may be adapted for this main engine. $T_{a}$ means boiling point at $101.325 \mathrm{kPa}, T_{c}$ means critical boiling point, $P_{c}$ means critical pressure, $O D P$ means ozone depletion potential value and GWP100 means 100 years' global warming potential value. 
Impact of waste heat recovery systems on energy...

Table 1: Thermodynamic properties of used working fluids.

\begin{tabular}{|l|c|c|c|c|c|l|}
\hline \multicolumn{1}{|c|}{ Fluid } & $T_{a},{ }^{\circ} \mathrm{C}$ & $T_{c},{ }^{\circ} \mathrm{C}$ & $P_{c}, \mathrm{MPa}$ & $O D P^{*}$ & $G W P 100$ & \multicolumn{1}{|c|}{ Fluid type } \\
\hline \hline R123 & 27.79 & 183.7 & 3.668 & 0.012 & 120 & isentropic fluid \\
\hline R141b & 32.07 & 204.2 & 4.249 & 0.086 & 630 & dry fluid \\
\hline R245fa & 14.91 & 154.1 & 3.639 & 0 & 950 & isentropic fluid \\
\hline n-pentane & 35.87 & 196.5 & 3.364 & 0 & 11 & dry fluid \\
\hline isopentane & 27.86 & 187.2 & 3.370 & 0 & 11 & dry fluid \\
\hline
\end{tabular}

* ozone depletion potential

\section{The research development of EEDI and EEOI}

\subsection{The research development of EEDI}

After several amendments to MARPOL Annex VI Regulations for the prevention of air pollution from ships by IMO, EEDI has been a measure of ships energy efficiency $(\mathrm{g} / \mathrm{ton} \times \mathrm{nmi})$ and scheduled to enter into force on 1 Jan. 2013. The value of EEDI is calculated by the following formula [1]:

$$
\begin{aligned}
E E D I= & \left\{\left(\prod_{j=1}^{M} f_{j}\right)\left(\sum_{i=1}^{n M E} P_{M E_{i}} \cdot C_{F M E_{i}} \cdot S F C_{M E_{i}}\right)\right. \\
& +\left(P_{A E} \cdot C_{F A E} \cdot S F C_{A E}\right) \\
& +\left[\left(\prod_{j=1}^{M} f_{j} \prod_{i=1}^{n P T I} P_{P T I_{i}}-\sum_{i=1}^{n e f f} f_{\text {eff }} \cdot P_{A E e f f_{i}}\right) C_{F A E} \cdot S F C_{A E}\right] \\
& \left.-\left(\sum_{i=1}^{n e f f} f_{\text {eff }} \cdot P_{\text {eff }} \cdot C_{F M E} \cdot S F C_{N E}\right)\right\} \\
& \times \frac{1}{f_{i} \cdot \text { Capacity } \cdot V_{\text {ref }} \cdot f_{w}},
\end{aligned}
$$

where $n M E$ and refer to number of main engines equipped in ship. Capacity means DWT of a ship. It must be noted that $65 \%$ of the dead weight ton should be used as Capacity in the case of container ships. $C_{F}$ is a nondimensional conversion factor between fuel consumption and $\mathrm{CO}_{2}$ emission based on fuel carbon content, for heavy oil $C_{F}=3.114$. The subscripts $M E$ 
and $A E$ refer to the main and auxiliary engine(s), respectively. $P_{M E_{i}}$ is $75 \%$ of the rated installed power for each main engine $(i)$ after having deducted any installed shaft generator(s), $P_{M E_{i}}=0.75\left(M C R_{M E_{i}}-P_{P T O_{i}}\right)$. $M C R_{M E_{i}}$ is the maximum continuous rating (MCR) power of main engine $i . P_{P T O_{i}}$ is $75 \%$ output of each shaft generator installed divided by the relevant efficiency of that shaft generator. $P_{P T I_{i}}$ is $75 \%$ of the rated power consumption of each shaft motor divide by the weighted averaged efficiency of the generator(s). $P_{e f f_{i}}$ is the output of the innovative mechanical energy efficient technology for propulsion at $75 \%$ main engine power. $P_{A E e f f_{i}}$ is the auxiliary power reduction due to innovative electrical energy efficient technology measured at $P_{M E_{i}}$. $P_{A E}$ is the required auxiliary engine power to supply normal maximum sea load including necessary power for propulsion machinery/systems and accommodation. $V_{r e f}$ is the reference speed in knots $(1 \mathrm{knot}=1.852 \mathrm{~km} / \mathrm{h})$ in a voyage. $S F C$ is the certified specific fuel consumption, measured in $\mathrm{g} / \mathrm{kWh}$, of the engines. $f_{j}$ is a correction factor to account for ship specific design elements. According to regulations of the international marine organization (IMO), $f_{j}$ can be set to be 0.77 for shuttle oil tankers with propulsion redundant system and 1.0 for other kinds of ships. A nondimensional coefficient $f_{w}$ indicates the decrease of speed in representative sea conditions of wave height, wave frequency and wind speed. $f_{e f f_{i}}$ is the availability factor of each innovative energy efficiency technology, $f_{\text {eff }}$ for waste energy recovery system should be 1.0. $f_{i}$ is the capacity factor for any technical/regulatory limitation on capacity, and can be assumed 1.0 if no necessity of the factor is granted.

Equation (1) shows that the reduction of the reference speed in a voyage $V_{\text {ref }}$, i.e., design speed and installation of waste heat recovery system are the main measures to lower the value of EEDI with no consideration of shaft generator(s), the innovative mechanical energy efficient technology, and other correction factors. Meanwhile, several organizations have developed programs to calculate the value of EEDI for different ship designers and ship owners. For example, Baltic and International Maritime Council (BIMCO) provide one EEDI calculator for free.

To compare the EEDI value of real ships, the reference line value of $E E D I$ recommended by international marine organization is employed in this paper.

$$
E E D I_{\text {ref }}=a \cdot \text { Capacity }^{-c},
$$

where $a$ is a coefficient related to ship type and Capacity means DWT of a ship. For large container ships, $a$ is 172.21 and $c$ is -0.2 [7]. 


\subsection{The research development of EEOI}

The EEOI (former operational CO2-Index) represents the actual transportefficiency of a ship in service and shall be part of the ship energy efficiency management (SEEMP). The value of EEOI is calculated by the following formula [5]

$$
E E O I=\frac{\sum_{j} F C_{j} \cdot C_{F j}}{m_{\text {cargo }} \cdot D},
$$

where $F C_{j}$ is the total fuel consumption in a voyage. $C_{F j}$ is a nondimensional conversion factor between fuel consumption and $\mathrm{CO}_{2}$ emission based on fuel carbon content. $m_{\text {cargo }}$ refers to tons of goods a cargo transported or TEU for standard containers, and $D$ is the sailed distance in nautical miles (nmi). Equation (3) shows that five contributing aspects could be taken into account to reduce the value of EEOI. They are the increase of sailed distance and load rate, reduction of time in port and design speed, and utilization of waste heat recovery system. It must be pointed out that several organizations have developed programs to calculate the value of EEOI for different ship designers and ship owners. For example, Totem Plus Ltd provide one EEOI calculator for free [6].

\section{Results and discussion}

\subsection{Unit cost benefit optimization of the waste heat recovery conceptual systems}

Instead of the exergy efficiency optimization, this paper selects the unit cost benefit as the objective function for optimization according to the ORC WHR working conditions.

The unit cost benefit can be expressed as

$$
U C B=\frac{A N B}{A N C_{T}},
$$

where $A N C_{T}$ is the annual total cost of the WHRS, in USD. $A N C_{T}$ consists of three parts, including the annual operating cost $A N C_{o}$, the exergy loss cost, $A N C_{I}$, and the original equipment cost $A N C_{I N V} . A N C_{T}$ is calculated by

$$
A N C_{T}=A N C_{o}+A N C_{I}+A N C_{I N V} .
$$


$A N B$ is the annual net profit and is expressed as

$$
A N B=A N I-A N C_{o},
$$

where $A N I$ is the value of electricity recovered by WHRS annually. $A N C_{o}$ is calculated as follows

$$
A N C_{o}=0.1 A N C_{T}
$$

For the thermoeconomic optimization, assumptions are made as follows:(1) the detailed structure parameters of the ORC WHR system have been carefully determined, which means that the optimization is only related to thermodynamic paremeters; (2) the condensing temperature is $35^{\circ} \mathrm{C}$ and the sea water temperature at the outlet of condenser is $30^{\circ} \mathrm{C}$.

Table 2 shows the results of optimization by net profit per cost optimization method of three exhaust gas waste heat recovery conceptual systems designed for the 10000 TEU container ship's main engine. In Tab. 2, $W_{\text {total }}$ and $W_{\text {net }}$ represent total exergy of the exhaust gas and net heat energy recovered by WHRS, respectively. It is obvious that organic Rankine cycle waste heat recovery conceptual system using R141b as working fluid has the best performance due to the highest value of $U C B$ which means net profit per cost of waste heat recovery systems.

Table 2: WHRS performances optimized by net profit per cost optimization method.

\begin{tabular}{|c|c|c|c|c|c|c|c|}
\hline $\begin{array}{c}\text { WHRS } \\
\text { type }\end{array}$ & $\begin{array}{c}T_{\text {steam.in }}, \\
{ }^{\circ} \mathrm{C}\end{array}$ & UCB & $\begin{array}{c}A N C_{T}, \\
\times 10^{6} \mathrm{USD}\end{array}$ & $\begin{array}{c}A_{\text {total.boiler }}, \\
\mathrm{m}^{2}\end{array}$ & $\begin{array}{c}W_{\text {net }} \\
\mathrm{kW}\end{array}$ & $\begin{array}{c}W_{\text {total }}, \\
\mathrm{kW}\end{array}$ & $\begin{array}{c}T_{\text {out.boiler }} \\
{ }^{\circ} \mathrm{C}\end{array}$ \\
\hline \hline $\mathrm{R} 123$ & 176 & 0.347 & 10.84 & 16477 & 1661 & 2162 & 137.7 \\
\hline $\mathrm{R} 141 \mathrm{~b}$ & 190.4 & 0.4179 & 10.08 & 17846 & 1842 & 2331 & 138 \\
\hline $\mathrm{R} 245 \mathrm{fa}$ & 146.7 & 0.205 & 8.662 & 13467 & 1317 & 1824 & 137.5 \\
\hline isopentane & 181.6 & 0.3122 & 9.259 & 14987 & 1579 & 2084 & 136.9 \\
\hline n-pentane & 190.2 & 0.3508 & 9.17 & 15659 & 1671 & 2157 & 137 \\
\hline water & 220.8 & 0.3437 & 3.835 & 12786 & 1279 & 1408 & 168.4 \\
\hline $\begin{array}{c}\text { combined } \\
\text { turbines }\end{array}$ & 270.8 & 0.3586 & 6.613 & 13484 & 3222 & 3389 & 158.5 \\
\hline
\end{tabular}




\subsection{The impact of WHRS on EEDI and EEOI}

In the referred research, software packages were developed to calculate the energy efficiency design index (EEDI) and energy efficiency operational indicator (EEOI) of the given large container ship.

\subsubsection{The impact of waste heat recovery conceptual systems on EEDI}

According to Eq. (2), one can get the value of the reference line value of EEDI, i.e., $16.835 \mathrm{gCO}_{2} /(\mathrm{t} \times \mathrm{nmi})$. Through Eq. (1), the EEDI of the 10000 TEU container ship without installing waste heat recovery conceptual systems can be calculated to be $13.60 \mathrm{gCO}_{2} /(\mathrm{t} \times \mathrm{nmi})$ and, respectively. In the case of main engine installing the waste heat recovery system, taking organic Rankine cycle WHRS using R141b as working fluid (the most appropriate working fluid) for example, the EEDI value of such a container is $12.95 \mathrm{gCO}_{2} /(\mathrm{t} \times \mathrm{nmi})$.

Analyzing the above three EEDI values, one can see that the 10000 TEU container ship's EEDI has decreased by $19.22 \%$ compared to the reference line value so that it has completely met IMO first stage's requirements (i.e., for a container ship which is above 15000 DWT should reduce its EEDI by $10 \%$ compared to the reference line value at first stage during Jan. 1, 2015 to Dec. 31, 2019) and very close to IMO second stage's requirements. A container ship which is above 15000 DWT should reduce its EEDI by $20 \%$ compared to the reference line value at second stage during Jan. 1, 2020 to Dec. 31, 2024).

The EEDI of the 10000 TEU container ship with R141b organic Rankine cycle WHRS can be decreased by $23.08 \%$ compared to the reference line value so that it has completely met IMO stage II's requirements by installing the waste heat recovery conceptual system.

\subsubsection{The impact of waste heat recovery conceptual systems on EEOI}

Suppose the normal operating state is: $D_{0}=6000 \mathrm{nmi}, R_{0}=100 \%, t s_{0}=$ $96 \mathrm{~h}, V_{0}=23 \mathrm{kn}(1 \mathrm{kn}=1.852 \mathrm{~km} / \mathrm{h})$, then the value of EEOI without waste heat recovery conceptual system can be gained, i.e., $154.8 \times 10^{-6}$ ton/(TEU $\times$ nmile). After installing waste heat recovery system (e.g., organic Rankine cycle waste heat recovery conceptual system using R141b as working fluid), the value of EEOI is calculated and gained, i.e., $147.8 \times 10^{-6}$ 
ton/(TEU $\times$ nmi $)$. It shows that the 10000 TEU container ship's EEOI has decreased by $4.52 \%$ after installing waste heat recovery system.

\section{Conclusion}

Energy efficiency design index (EEDI) and energy efficiency operational indicator (EEOI) are important measures to evaluate energy efficiency and $\mathrm{CO}_{2}$ emissions of vessels and are advocated to make ships becoming more and more efficient.

Waste heat in emission gas of large containers is quite quantitative but with a low emission temperature. Modern WHRS is technologically possible to be equipped not only to improve total energy utilization efficiency but also to reduce greenhouse gas emissions.

In this paper, three types of WHRS are proposed to recover waste heat from a 10000 TEU conceptual large container ship driven by a modern low speed marine diesel engine. To calculate the EEDI and EEOI of the given large container ship, two software packages are developed. Results indicate that the large container ship itself can reach the IMO requirements of EEDI at the first stage with a reduction factor $10 \%$ under the reference line value, the proposed waste heat recovery systems can improve the ship EEDI reduction factor to $20 \%$ under the reference line value. WHRS could improve the overall ship efficiency and reduce emissions simultaneously.

Acknowledgments We gratefully acknowledge the financial support of the Qing-Lan Project of Jiangsu Province under contract No. 161220605, Studying Abroad Program for Excellent Young Scholars sponsored by Jiangsu Provincial Department of Education and the Nanjing Forestry University (201610298022Z).

Received 3 December 2016

\section{References}

[1] Draft guidelines on the method of calculation of the attained energy efficiency design index for new ships $[C]$. Annex 1, MEPC 62/5/4, Marine Environment Protection Committee, IMO, 8 April, 2011.

[2] MAN BESW Diesel A/S. Main Engine Room Data for 10S90ME-C9.2-TII. Internal Data. 
[3] MAN BEGW Diesel A/S. Thermo Efficiency System for Reduction of Fuel Consumption and CO2 Emission. MAN B\&W brochure, 2013.

[4] Baltic and International Maritime Council. EEDI Calculator, http://www.bimco.org/en/Products/EEDI.aspx.

[5] International Maritime Organization. Guidelines for Voluntary Use of the Ship Energy Efficiency Operational Indicator (EEOI). IMO, London 2014.

[6] Totem Plus Ltd. EEOI Calculator, http://www.totemplus.com.

[7] Mepc.214(63). Guidelines on survey and certification of the energy efficiency design index (EEDI), 2012

[8] Yang Min-Hsiung,YeH, Rong-HuA: Thermo-economic optimization of an organic Rankine cycle system for large marine diesel engine waste heat recovery. Energy 82(2015), 256-268.

[9] Zheshu Ma, Jieer Wu: Efficiency optimization of a closed IFGT cycle working under two variable-temperature heat reservoirs. Arch. Thermodyna. 32(2011), 2, $3-20$.

[10] Hajabdollahi Zahra, Hajabdollahi Farzaneh, Tehrani Mandi: Thermoeconomic environmental optimization of Organic Rankine Cycle for diesel waste heat recovery. Energy 63(2013), 142-151. 